\title{
Effects of lesion size, shape, and resection amount on the final length of the scar in staged excision: An animal experiment in pigs
}

Jinwook Jeong ${ }^{1}$, Minwoo Park², Daegu Son ${ }^{2}$

${ }^{1}$ View Aesthetic Plastic Surgery Clinic, Seoul; ${ }^{2}$ Department of Plastic and Reconstructive Surgery, Keimyung University School of Medicine, Daegu, Korea
Background In staged excision procedures, it is difficult to estimate the number of excisions that will be required and the extent of scar lengthening. The purpose of this study was to investigate the effects of the size, shape, and resection amount of lesions on the outcomes of staged excision through an animal experiment.

Methods In total, 20 ellipses with five different designs $(n=4)$ were evaluated on pig skin. The experiment consisted of two groups: group 1 had excisions of the same length, but with different widths, while group 2 had excisions of the same size, but with different amounts of resection. The size of the lesions and the amount of resection were analyzed in terms of the ratio of length (long axis) and width (short axis) (S/L ratio).

Results In the first group, initial ellipses measuring $5 \times 4,5 \times 3$, and $5 \times 2 \mathrm{~cm}$ increased in size to $9.25 \pm 0.07$ (185\%), $8.55 \pm 0.07$ (171\%), and $8.10 \pm 0.14 \mathrm{~cm}$ (162\%), respectively. In the second group, in which all ellipses measured $5 \times 3 \mathrm{~cm}$, those with a resection amount of $5 \times 1.5,5 \times 2$, and $5 \times 2 \mathrm{~cm}$ with a fish fin grew to $8.75 \pm 0.15(175 \%), 8.55 \pm 0.07(171 \%)$, and $8.60 \pm 0.17 \mathrm{~cm}(172 \%)$, respectively. In group 1 , the larger the $\mathrm{S} / \mathrm{L}$ ratio, the longer the final length. In group 2, a greater resection amount was associated with a shorter final length. Conclusions We believe that the measurements of this study in terms of shape, size, and excision amount will be reasonable predictive references for staged excision procedures.

Keywords Nevus, pigmented / Margins of excision / Wound closure technique

\section{INTRODUCTION}

Single-stage complete excision of a large scar and nevus without distortion of the normal anatomy is challenging. Therefore, tissue expansion and other reconstructive options have been adopted to solve these problems [1]. Staged excision is used to remove large

Received: Mar 16, 2020 Revised: Apr 7, 2020 Accepted: Apr 7, 2020 Correspondence: Daegu Son Department of Plastic and Reconstructive Surgery, Keimyung University School of Medicine, 1095 Dalgubeol-daero, Dalseo-gu, Daegu 42601, Korea

Tel: +82-53-258-7817, Fax: +82-53-258-4590, E-mail: handson@dsmc.or.kr

Copyright @ 2020 The Korean Society for Aesthetic Plastic Surgery.

This is an Open Access article distributed under the terms of the Creative Commons At tribution Non-Commercial License (https://creativecommons.org/licenses/by-nc/4.0/) which permits unrestricted non-commercial use, distribution, and reproduction in any medium, provided the original work is properly cited. www.e-aaps.org lesions in multiple steps under local anesthesia with an interval of 6 to 12 months.

Staged excision, which was first described in plastic surgery in 1915 by Morestin [2], is a well-established technique that remains important for removing congenital nevi, areas of alopecia, tattoos, and scars [3]. Staged excision relies on the principle of recruitment of adjacent normal skin through the stress relaxation property of skin at each procedure to cover a defect in stages [4]. Many other treatment options have been proposed, but staged excision is still the preferred treatment modality for congenital nevi if the lesion can be excised in three or fewer stages without distorting the adjacent structures.

In the surgical treatment of skin lesions, it is very important to minimize scar lengthening, wound dehiscence, skin necrosis, and anatomical disfiguration without using a local flap or tissue expansion. Therefore, staged excision is often the reconstructive option 
of choice [5]. Nevertheless, some considerations should be kept in mind when performing a staged excision, including the number of excisions, the amount excised at each stage, and the excision patterns. Estimating the scar length after a series of excisions is also difficult because every lesion is unique in terms of its size, shape, and location. Previous studies of staged excision did not provide much information regarding these issues, and textbooks present the basic principles and technique to a very limited extent [2-5].

To address this gap in the literature, an animal study was performed to investigate these elements in a second-stage procedure to determine the most effective method for minimizing scar lengthening. The purpose of this study was to investigate the effects of the size, shape, and resection amount of lesions on the outcomes of staged excision through an animal experiment.

\section{METHODS}

\section{Animal experiments}

Staged excisions were performed on the backs of pigs, the skin of which has been proven to be similar to that of humans. This study was carried out in accordance with the regulations outlined by the Keimyung University Animal Research Ethics Committee. Two female Yorkshire pigs ( 3 months old, weighing $40 \mathrm{~kg}$ ) without skin disease were used. The environment was maintained from $20^{\circ} \mathrm{C}$ to $23^{\circ} \mathrm{C}$ and $65 \%$ humidity, with a 12-hour light/dark cycles.

Sedation was performed using an intramuscular injection of 2.2 $\mathrm{mg} / \mathrm{kg}$ azaperone (Stresnil, Janssen, Beerse, Belgium), and $37 \mathrm{mg} /$ kg propofol (Diprivan-PFS, AstraZeneca Korea, Seoul, Korea) was injected into the external ear vein to induce anesthesia. Glucuronic
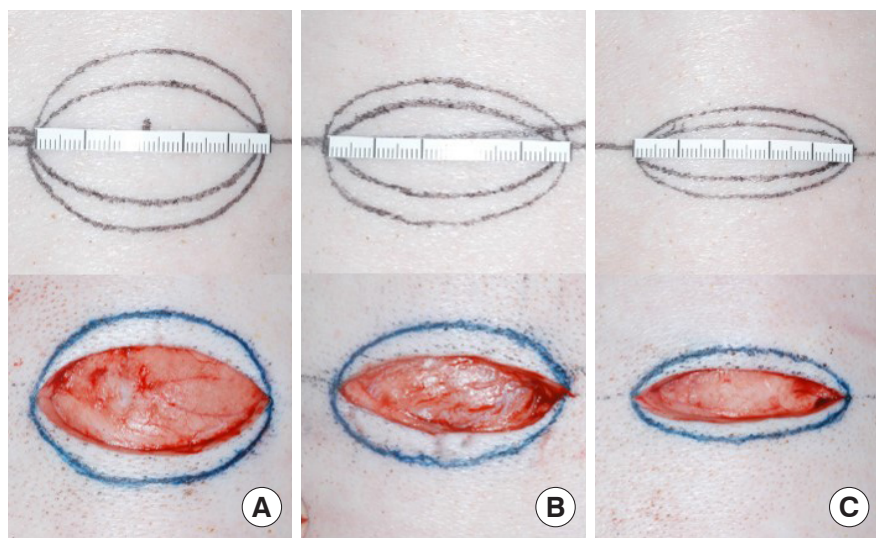

Fig. 1. Design of the ellipse and first-stage excision patterns with the same ratio of excision. (A) Type A: an ellipse measuring $5 \times 4 \mathrm{~cm}$, from which two-thirds of the area $(5 \times 2.66 \mathrm{~cm})$ was excised in the first-stage excision and a full-thickness skin defect was made. (B) Type B: an ellipse measuring $5 \times 3 \mathrm{~cm}$ with a $5 \times 2 \mathrm{~cm}$ first-stage excision. (C) Type $C$ : an ellipse measuring $5 \times 2 \mathrm{~cm}$ with a $5 \times 1.33 \mathrm{~cm}$ firststage excision. acid chlorohexidine (Microshield; Johnson \& Johnson, New Brunswick, NJ, USA) and povidone-iodine were used for sterilization after shaving the thick hairs with a razor.

\section{Model designs}

The models were divided into two groups: group 1 had defects with an elliptical shape, with a length (long axis) of $5 \mathrm{~cm}$, but three different widths (short axis) $(4 \mathrm{~cm}, 3 \mathrm{~cm}$, and $2 \mathrm{~cm}$ ). In this group, the first excision was performed with the same ratio (two-thirds of the original size). The ratio of length (long axis) and width (short axis) ( $\mathrm{S} / \mathrm{L}$ ratio) was used as a measure of the size and shape. The S/L ratio was calculated using the following formula:

$\mathrm{S} / \mathrm{L}$ ratio $=$ short axis (width)/long axis (length)

Supposing that the length of the long axis is the same, a larger S/ $\mathrm{L}$ ratio would result in a larger size and a rounder shape, and a smaller $\mathrm{S} / \mathrm{L}$ ratio would result in a smaller size and a more elliptic shape. The area of the ellipse can be calculated as ellipse area is $\mathrm{A}=\pi \times$ long axis $/ 2 \times$ short axis $/ 2$ and the long axis length. If the length of the long axis remains the same, the area will be proportional to the short axis. Two-thirds of the original area could be excised in the first stage by choosing two-thirds of the short axis length as the excision point. Therefore, the nevi comprised ellipses measuring $5 \times 4$, $5 \times 3$, and $5 \times 2 \mathrm{~cm}$, resulting in $\mathrm{S} / \mathrm{L}$ ratios of $0.8,0.6$, and 0.4 , respectively. Therefore, the first excised elliptical areas were $5 \times 2.66$ $\mathrm{cm}, 5 \times 2 \mathrm{~cm}$, and $5 \times 1.33 \mathrm{~cm}$, with S/L ratios of $0.53,0.40$, and 0.26 , respectively (Fig. 1).

In the second group, elliptical defects were designed with the same size, $5 \times 3 \mathrm{~cm}$, but with three different excision areas. The amounts of the first excised areas were as follows: $5 \times 2 \mathrm{~cm}$, elliptical; $5 \times 2 \mathrm{~cm}$, elliptical with two fish fins; and $5 \times 1.5 \mathrm{~cm}$, elliptical (Fig. 2). These shaped yielded S/L ratios of $0.4,0.4$ with fish fins, and 0.3 , respectively. The new design was composed of one ellipse

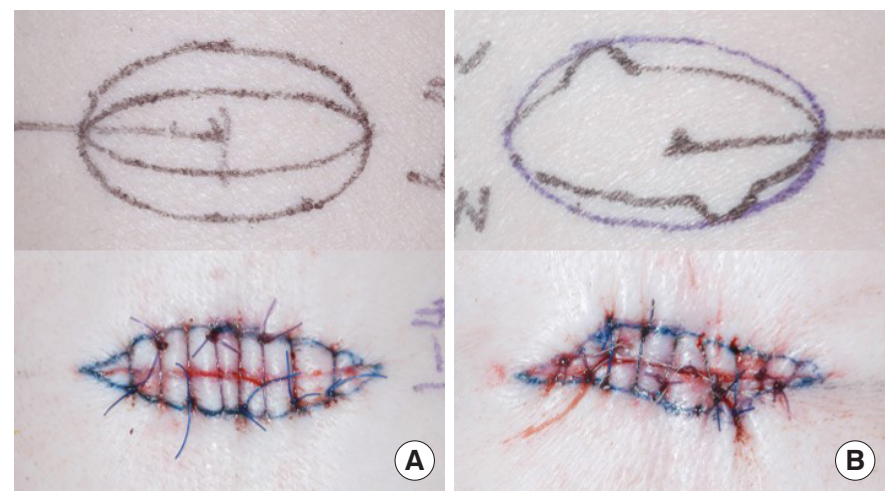

Fig. 2. Design of the ellipse and excision patterns with various amounts of excision. (A) Type D: an ellipse measuring $5 \times 3 \mathrm{~cm}$ and a $5 \times 1.5 \mathrm{~cm}$ first-stage excision. (B) Type $E$ : an ellipse measuring $5 \times 3 \mathrm{~cm}$, from which an area measuring $5 \times 2 \mathrm{~cm}$ with two fish fins was excised in the first-stage excision and closed. 
and two fish fins on both lateral quarters of the arc of an ellipse diagonally. The size of the base of the fish fin was $1 \mathrm{~cm}$, and the height was designed to be directly under the lesion (Fig. 3). Therefore, more tissue could be excised, which was expected to reduce the scar length. The first and second groups had the same ellipse model $(5 \times 3 \mathrm{~cm})$ as a control, resulting in a total of five different staged excision models. Since cephalic wounds contract more quickly in pigs, the defects in each experimental group were placed between the scapula and the iliac crest [6].

\section{Staged excision}

A predesigned excision pattern was drawn on the skin over the paravertebral muscles of the pigs with a permanent marker. Each design was set with a spacing of $8 \mathrm{~cm}$ to reduce mutual influence. The first excision was performed with a No. 10 scalpel blade, and consequently a full-thickness skin defect above the fascia was made. Subsequently, the area of minimal skin undermining was closed

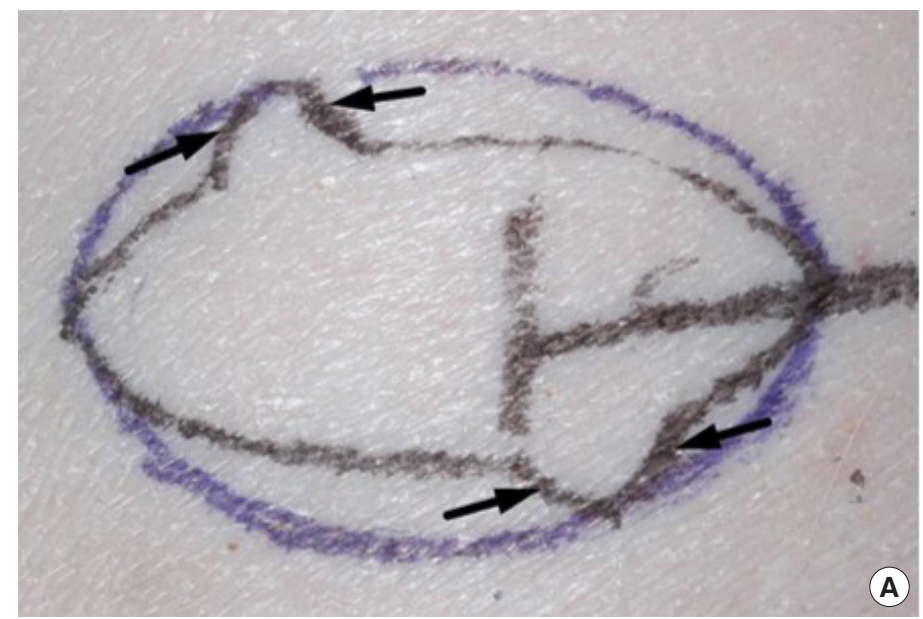

with Vicryl 2-0 and Nylon 2-0 sutures. The second excision was performed 2 weeks after the first excision, and all remaining areas were excised with a fusiform ellipse shape. The vertex angle of both ends of the fusiform ellipse was consistently $30^{\circ}$ in all procedures. Subsequent treatments included sterile wound dressing and antibiotic injections after the procedure. The wounds were treated in the same way in each animal according to a predefined protocol.

\section{Measurements and statistical analysis}

The lengths of the long and short axis were measured with a paper ruler at the first and second excision preoperatively and postoperatively. The S/L ratio was simultaneously calculated. For the statistical analysis, the t-test (R statistical package, version 3.6.1; R Foundation for Statistical Computing, Vienna, Austria) was used to analyze differences in length in each group. To explore group-by-group differences, the Tukey honest significant difference (R statistical package, version 3.6.1) was used.

Fig. 3. (A) Preoperative design of fish fins (arrows) in the first-stage excision. (B) Postoperative view of the first-stage excision. In the secondstage excision, the apices were brought closer together perpendicularly (thin arrows), whereas the central portion was stitched diagonally (thick arrows).

Table 1. Summary of the experiment and results of the first group

\begin{tabular}{|c|c|c|c|c|c|c|}
\hline \multirow[b]{2}{*}{ Type } & \multirow[b]{2}{*}{ Design } & \multirow{2}{*}{$\begin{array}{c}\text { Ellipse } \\
\text { size }(\mathrm{cm})\end{array}$} & \multicolumn{2}{|c|}{ First stage $(\mathrm{cm})$} & \multicolumn{2}{|c|}{ Second stage $(\mathrm{cm})$} \\
\hline & & & $\begin{array}{l}\text { Excision } \\
\text { amount }\end{array}$ & $\begin{array}{c}\text { After } \\
\text { excision }\end{array}$ & Design & $\begin{array}{l}\text { Final } \\
\text { length }\end{array}$ \\
\hline$A$ & & $\begin{array}{l}5 \times 4 \\
(0.8)\end{array}$ & $\begin{array}{c}5.00 \times 2.66 \\
(0.53)\end{array}$ & $\begin{array}{c}5.98 \times 1.65 \\
(0.28)\end{array}$ & $\begin{array}{c}8.60 \times 2.20 \\
(0.26)\end{array}$ & $\begin{array}{r}9.25 \pm 0.07 \\
P<0.05^{a l}\end{array}$ \\
\hline B & & $\begin{array}{l}5 \times 3 \\
(0.6)\end{array}$ & $\begin{array}{c}5.00 \times 2.00 \\
(0.40)\end{array}$ & $\begin{array}{c}5.43 \times 1.40 \\
(0.26)\end{array}$ & $\begin{array}{c}7.25 \times 1.75 \\
(0.24)\end{array}$ & $\begin{array}{r}8.55 \pm 0.07 \\
P<0.01^{a l}\end{array}$ \\
\hline C & & $\begin{array}{l}5 \times 2 \\
(0.4)\end{array}$ & $\begin{array}{c}5.00 \times 1.33 \\
(0.26)\end{array}$ & $\begin{array}{c}5.05 \times 1.23 \\
(0.24)\end{array}$ & $\begin{array}{c}6.90 \times 1.60 \\
(0.23)\end{array}$ & $\begin{array}{c}8.10 \pm 0.14 \\
P<0.05^{a l}\end{array}$ \\
\hline
\end{tabular}

The values in parentheses indicate the ratio of length (long axis) and width (short axis).

${ }^{a}$ Statistically significant.
Table 2. Summary of the experiment and results of the second group

\begin{tabular}{|c|c|c|c|c|c|c|}
\hline \multirow[b]{2}{*}{ Type } & \multirow[b]{2}{*}{ Design } & \multirow{2}{*}{$\begin{array}{c}\text { Ellipse } \\
\text { size } \\
(\mathrm{cm})\end{array}$} & \multicolumn{2}{|c|}{ First stage $(\mathrm{cm})$} & \multicolumn{2}{|c|}{ Second stage $(\mathrm{cm})$} \\
\hline & & & $\begin{array}{l}\text { Excision } \\
\text { amount }\end{array}$ & $\begin{array}{c}\text { After } \\
\text { excision }\end{array}$ & Design & $\begin{array}{l}\text { Final } \\
\text { length }\end{array}$ \\
\hline B & & $\begin{array}{l}5 \times 3 \\
(0.6)\end{array}$ & $\begin{array}{c}5.00 \times 2.00 \\
(0.40)\end{array}$ & $\begin{array}{c}5.43 \times 1.40 \\
(0.26)\end{array}$ & $\begin{array}{c}7.25 \times 1.75 \\
(0.24)\end{array}$ & $\begin{array}{l}8.55 \pm 0.07 \\
P<0.01^{a l}\end{array}$ \\
\hline D & & $\begin{array}{l}5 \times 3 \\
(0.6)\end{array}$ & $\begin{array}{c}5.00 \times 1.50 \\
(0.30)\end{array}$ & $\begin{array}{c}5.50 \times 1.53 \\
(0.28)\end{array}$ & $\begin{array}{c}8.50 \times 2.30 \\
(0.27)\end{array}$ & $\begin{array}{c}8.75 \pm 0.15 \\
P<0.01^{a)}\end{array}$ \\
\hline $\mathrm{E}$ & & $\begin{array}{l}5 \times 3 \\
(0.6)\end{array}$ & $\begin{array}{c}5.00 \times 2.00 \\
\text { Fish-fin shape }\end{array}$ & $\begin{array}{l}5.15 \times 1.18 \\
(0.23)\end{array}$ & $\begin{array}{c}8.37 \times 2.13 \\
(0.25)\end{array}$ & $\begin{array}{l}8.60 \pm 0.17 \\
P<0.01^{a l}\end{array}$ \\
\hline
\end{tabular}

The values in parentheses indicate the ratio of length (long axis) and width (short axis).

${ }^{\text {a) }}$ Statistically significant. 


\section{RESULTS}

In total, 20 ellipses with five different designs $(n=4)$ were created and there were no specific complications except for re-suturing of two ellipses measuring $5 \times 4 \mathrm{~cm}$ due to wound dehiscence on the first day postoperatively, which may have resulted from wound tension. As the pigs grew, two points marked as $5 \mathrm{~cm}$ apart became $5.2 \mathrm{~cm}$ and $5.3 \mathrm{~cm}$ apart, respectively, after 2 weeks. The observed length differed between after the first excision and 2 weeks later due to creep and relaxation, as well as growth (Tables 1,2).

In the first group, with defects of the same length but different width; the initial $5 \times 4 \mathrm{~cm}$ ellipse grew to $9.25 \pm 0.07 \mathrm{~cm}$ (185\% longer than the original length) after the final excision. The initial $5 \times 3 \mathrm{~cm}$ ellipse increased in size to $8.55 \pm 0.07 \mathrm{~cm}(171 \%)$ after the final excision. The initial $5 \times 2 \mathrm{~cm}$ ellipse increased in size to $8.10 \pm$ $0.14 \mathrm{~cm}(162 \%)$ after the final excision (Table 1). The increase in final length was directly proportional to the S/L ratio.

In the second group, with ellipses of the same size and different amounts of excision, the ellipse with an initial excision of $5 \times 1.5$ $\mathrm{cm}$ increased in size to $8.75 \pm 0.15 \mathrm{~cm}(175 \%)$ after the final excision. The ellipse with an initial excision of $5 \times 2 \mathrm{~cm}$ grew to $8.55 \pm$ $0.07 \mathrm{~cm}(171 \%)$ after the final excision (Table 2). Therefore, a larger first-stage excision resulted in a smaller secondary excision, which reduced the final length. The fish-fin pattern was lengthened to $8.60 \pm 0.17 \mathrm{~cm}$ (172\%) (Table 2).

In most cases, the differences in length were statistically significant. In all types, the differences between the final length (second measurement) and initial length were statistically significant. Type $C$ had the smallest average difference between the final length and initial length, followed by types B, E, D, and A. In other words, on average, the two dots grew apart the least when the incision method of type $\mathrm{C}$ was used ( $3.1 \mathrm{~cm}$ increase), and the dots grew apart the most when the incision method in type A was used $(4.25 \mathrm{~cm}$ increase).

Analysis of variance revealed that there was a statistically significant difference among the five different incision types, with higher than $99.9 \%$ confidence. The difference in the final excision length between type $\mathrm{B}$ and type $\mathrm{A}$ was $-0.7 \mathrm{~cm}$; in other words, the final excision length in type B was $0.7 \mathrm{~cm}$ shorter than that in type A. With $95 \%$ confidence, the difference between type $B$ and type A was between $0.2 \mathrm{~cm}$ and $1.20 \mathrm{~cm}$. The difference between types $A$ and B was statistically significant at a $99 \%$ level $\left(\mathrm{P}_{\text {adj }}<0.01\right)$.

\section{DISCUSSION}

This study demonstrated that in staged excision procedures, larger lesions and those with a rounder shape resulted in longer and when a large amount of tissue was surgically resected in the first stage of excision the final scar is shorter final length. This result was expected. However, to the best of our knowledge, no previous papers have published objective measurements regarding this phenomenon [2-5]. The primary advantage of this study is that in the skin of pigs, which most closely resembles human skin $[7,8]$, lesions were created and resected under specific conditions to obtain objective measurements.

The standard technique of staged excision is a series of elliptical excisions. Many studies of elliptical excisions have been published, and most common pattern used is a fusiform ellipse with a vertex angle of $30^{\circ}$ or less and a length-to-width ratio between 3:1 to 4:1 to minimize the formation of dog ears, as these ratios result in a long scar without the tissues bunching up at the ends [9]. The choice of a length-to-width ratio depends on the case and the surgeon's preference. Tilleman et al. [10] reported a mean length-to-width ratio of 3.13:1 (S/L ratio $=0.32)$ in 26 non-melanomatous malignant tumor excisions. This ratio, which was selected as a reference and expressed as a simple $\mathrm{S} / \mathrm{L}$ ratio, is quite useful because it reflects whether nevi have an elliptic or circular shape. A S/L ratio close to 1 corresponds to a circular ellipse, while a ratio of 0 reflects a shallow ellipse. Complete excision of an ellipse with an S/L ratio of 0.34 without a dog ear required lengthening of the long axis, which maximized the scar length after complete excision. Performing another repeat excision in a case with a relatively high $\mathrm{S} / \mathrm{L}$ ratio reduced the final scar length. Therefore, one of the factors that contributes to the formation of a longer final scar is the height of the extrusion of an ellipse. This means that the height of the extrusion of the ellipse is proportional to the length of the long axis and the final scar [11].

In the ellipses measuring $5 \times 4,5 \times 3$ and $5 \times 2 \mathrm{~cm}$, the $\mathrm{S} / \mathrm{L}$ ratio changed from 0.8 to 0.28 , from 0.6 to 0.26 , and from 0.4 to 0.24 after the first excision, and the final ratios were $<0.32$. Therefore, a two-stage excision is sufficient to complete the excision without increasing the long axis and vertical angle $(\theta)$. This suggests that if the $\mathrm{S} / \mathrm{L}$ ratio is $>0.32$ after the first excision of a lesion, the staged excision should be repeated before the final stage to minimize final scar lengthening.

In the model where the ellipses were of the same size, but with a different amount of excision, the findings for $5 \times 3 \mathrm{~cm}$ ellipses with a $5 \times 2$ or $5 \times 1.5 \mathrm{~cm}$ excision suggest that the first excision amount has an impact on the final scar length. Every effort should be made to excise more tissue during the first excision, to the extent that is possible to approximate the skin approximate without a high level of tension despite the existence of a dog ear or depression. A depression, dog ear, or widened scar after the first excision can be resolved in the final excision, during which the surgeon should focus on reducing the level of tension and scar length, as well as minimizing the deformity and dog ear to improve the aesthetics. However, it is important to keep in mind that wound healing should be satisfactory between surgery.

A modified S-plasty distributes the vectors of tension in two different directions: at the apices and in the central part. The apices 

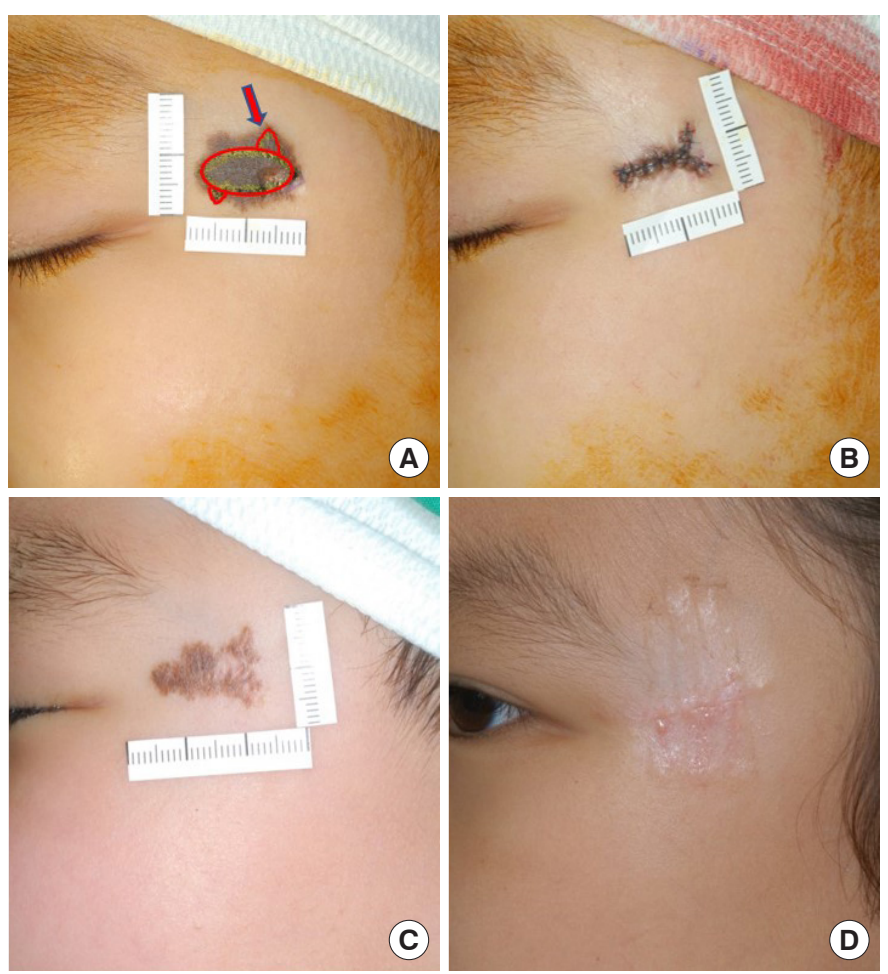

Fig. 4. Clinical application of the fish-fin design. (A) The position of the fish fin (arrow) can be changed according to the geometric shape of the lesion. However, the incision should not be gathered in one place in the form of a cross. (B) Immediate postoperative view of the first-stage serial excision. (C) Ten months after the first-stage operation, the lesion was wider than it was immediately after the operation. (D) After the third-stage excision, the lesion was completely removed and there was no change in surrounding structures.

are brought closer together perpendicularly, whereas the central portion is stitched diagonally. The closure of this final part is accomplished by applying oblique traction on the edges and distributing the vector of tension in a different direction from the apices. This provides a greater inclination of the axis of the suture, and traction on the suture line can be reduced by approximately one-third compared to a simple elliptical excision [12]. In addition, the height of the extrusion is also reduced by approximately $40 \%$ [13]. This inspired us to make a new design, in which two small fish-fin excisions are added on the opposite site of the ellipse. In this experiment, the fish-fin group was expected to show the shortest length from the geometric point of view, but the results were not significantly different from those of type $B$. The reason for this is that the length was the shortest immediately after the first operation, but the effect was lost during the wound healing period before the second operation. Therefore, choosing a design that maximizes the amount of excision is a favorable method in principle, but the underlying procedures may be too complicated to affect wound healing.
However, in actual clinical circumstances, the fish-fin shape was very useful in cases where the lesion was large enough or had a geometric shape for which the fish-fin design could be applied well (Fig. 4).

The primary limitation of our study is the small number of ellipses in each group. However, since this was an animal experiment involving basic biological research and the standard deviation of the measurements in each group was small, the measurements in this study can serve as a reasonable reference for predicting the results of staged excision.

The main purpose of performing staged excision for a lesion, such as a nevus, is to eliminate the lesion completely and minimize the final scar. The $\mathrm{S} / \mathrm{L}$ ratio was used to estimate the scar lengthening and the number of excisions. To minimize the length of the final scar, the majority of the area should be excised prior to the final excision and the final excision should be performed with a lower S/ $\mathrm{L}$ ratio without tension. We believe that the measurements of this study in terms of shape, size, and excision amount will serve as reasonable predictive references for staged excision procedures.

\section{NOTES}

\section{Conflict of interest}

No potential conflict of interest relevant to this article was reported.

\section{Ethical approval}

The experiments were conducted after receiving approval from the Keimyung University Animal Research Ethics Committee (KM2009-02).

\section{Patient consent}

The patients provided written informed consent for the publication and the use of their images.

\section{ORCID}

Jinwook Jeong

Minwoo Park

Daegu Son

https://orcid.org/0000-0002-7719-6991

https://orcid.org/0000-0003-2156-1053

https://orcid.org/0000-0002-4653-1048

\section{REFERENCES}

1. Han KH, Sohn DG, Kang JS. Reconstruction of the face using tissue expansion. J Korean Soc Aesthetic Plast Surg 1995;1:29-43.

2. Converse JM. La réduction graduelle des difformités tégumentaires: $\mathrm{H}$. Morestin, M.D., Paris (Bull. et mém. Soc. chir. Paris, 41: 1233, 1915. Plast Reconstr Surg 1968;42:163-72.

3. Gosain AK, Santoro TD, Larson DL, et al. Giant congenital nevi: a 20year experience and an algorithm for their management. Plast Reconstr Surg 2001;108:622-36.

4. Quaba O, Shoaib T, Durrani AJ, et al. A user's guide for serial excision. 
J Plast Reconstr Aesthet Surg 2008;61:712-5.

5. Arneja JS, Gosain AK. Giant congenital melanocytic nevi of the trunk and an algorithm for treatment. J Craniofac Surg 2005;16:886-93.

6. Kwak M, Son D, Kim J, et al. Static Langer's line and wound contraction rates according to anatomical regions in a porcine model. Wound Repair Regen 2014;22:678-82.

7. Sullivan TP, Eaglstein WH, Davis SC, et al. The pig as a model for human wound healing. Wound Repair Regen 2001;9:66-76.

8. Wang JF, Olson ME, Winkfein RJ, et al. Molecular and cell biology of porcine HSP47 during wound healing: complete cDNA sequence and regulation of gene expression. Wound Repair Regen 2002;10:230-40.

9. Leshin B. Proper planning and execution of surgical excisions. In: Wheeland RG, editor. Cutaneous surgery. Philadelphia: W.B. Saun- ders; 1994. p. 171-7.

10. Tilleman TR, Neumann MH, Smeets NW, et al. Waste of skin in elliptical excision biopsy of non-melanomatous skin cancer. Scand J Plast Reconstr Surg Hand Surg 2006;40:352-6.

11. Yoshida H, Tsutsumi S, Mizunuma M, et al. Three-dimensional finite element analysis of skin suture. Part 1: spindle model and S-shaped modified model. Med Eng Phys 2000;22:481-5.

12. Paolo B, Stefania R, Massimiliano C, et al. Modified S-plasty: an alternative to the elliptical excision to reduce the length of suture. Dermatol Surg 2003;29:394-8.

13. Yoshida H, Tsutsumi S, Mizunuma M, et al. A surgical simulation system of skin sutures using a three-dimensional finite element method. Clin Biomech (Bristol, Avon) 2001;16:621-6. 